\title{
Parents' Beliefs on Philippine Educational and Curriculum Practices: What Educators Can Learn from Them
}

\author{
Romina P. Beltran-Almazan, Cristina Victoria Patolot-Velasco, Ronnel R. Almazan, and Amelia C. Fajardo \\ College of Education, University of the Philippines, Diliman, Quezon City, Philippines
}

\author{
How to cite \\ Beltran-Almazan, R. P., Patolot-Velasco, C. V., Almazan, R. R., \& Fajardo, A. C. (2020). Parents' Beliefs on Philippine \\ Educational and Curriculum Practices: What Educators Can Learn from Them. Asia Pacific Journal on Curriculum \\ Studies, 3(1), 1-9. https://doi.org/10.53420/apjcs.2020.1
}

\begin{abstract}
Parents are part of the school community. However, schools have neglected to tap parents' opinions and perceptions of new programs for implementation (Ornstein \& Hunkins, 2009). Upon this background, Dodd (1988) conducted her research to gain a better understanding of the curriculum and practices parents favored, including their underlying beliefs about teaching and learning high school English. This study replicated Dodd's (1998) research to explore the understanding of educational practices that Filipino parents prefer in the light of curriculum innovations, particularly the K to 12 Junior High School English subject. Key informant interview (KII) was used as the main data-gathering technique following Dodd's (1988) interview protocol. The KII information was subjected to thematic analysis to gather the major ideas that are essential in answering the research questions. The findings revealed that parents' beliefs are based on their own and their children's experiences and their children's well-being. Thus, their approval of the curriculum and educational practices are largely dependent on how these will affect and benefit their children based on their understanding of policies and practices. They further place a significant value on teachers' role in the implementation of the curriculum as facilitators of learning and academic leaders who could help their children maximize their potential. Parents can also help identify problems concerning curriculum implementation, teachers' roles and duties, teacher-parent and teacher-student relationships, and school environment. In this regard, home-school partnerships can be strengthened to gain parents' support and obtain valuable insights on how curriculum and educational practices affect their children. Therefore, cultivating parent involvement is ultimately beneficial for schools as this provides essential feedback on the introduction and implementation of curricular reforms and the improvement of practices.
\end{abstract}

Keywords: curriculum implementation, English curriculum, basic education curriculum, parent engagement

\section{Introduction}

Stakeholders are collaborators in the decision-making process in curriculum development (Greene, 1987). As the people overseeing the students' welfare at home, parents play a critical role in supporting the school's program at the very heart of the students' most immediate environment. Similarly, parents are part of the school community whose support for school change is essential (Dodd, 1998). Parents should be important considerations as a constant and principal component of curriculum (Sad \& Gurbuzturk in Bartolome, Mamat \& Masnan, 2017). However, schools have neglected to tap parents' opinions and perceptions of new programs for implementation (Ornstein\& Hunkins, 2009). Johnson and Immerwahr (1994) point out that efforts to reform and improve the nation's schools have encountered serious roadblocks often in the form of parents' opposition, which stems from parents' belief that public schools failed to provide a safe, orderly environment, and high teaching standards. Dodd (1988) emphasizes the importance of engaging parents in educational and curricular decisions as partners in implementing the program and other school reforms so there would be less resistance in the change transition.

Parents' beliefs on literacy and education are a result of two demographic factors, namely, parents' education level and socioeconomic status. (Lynch, Anderson, Anderson, \& Shapiro, 2006; Rose \& Elicker, 2008 in Fetalvero, 2010). Studies showed that parents who are less literate and who come from a lower social-economic status prefer a more traditional approach to learning and direct teaching activities (Stipek, Milburn, Clements, \& Daniels, 1992; Lynch, Anderson, Anderson, \& Shapiro, 2006; Fetalvero, 2010). On the other hand, parents who have higher literacy and belong to a higher socio-economic status favored a less structured and wider range of activities for literacy (Stipek, et al, 1992; Lynch, et al 2006; Fetalvero, 2010). 
In the Philippines, where there is a dearth of literature on parents' educational beliefs, parents raise their children with authoritarian behavior (Alampay, cited in Bartolome, et al, 2017). They are keen on being involved in their children's education, believing that their academic involvement has a positive relationship with scholastic performance (de Guzman, et al 2008; Bartolome, Mamat \& Masnan, 2017). It is for this reason that the level of involvement in their children's education is one factor that affects parents' choice of school, apart from affordability and the quality of human resources (de Guzman, et al.,2008).

Alongside school-based reforms are government-led innovations in education. The latest of which is the implementation of the K to 12 Curriculum in the Philippines under the Enhanced Basic Education Act of 2013. Some of the most significant contributions of this reform to the curriculum are the inclusion of Grades 11 and 12 or senior high school (SHS) in basic education and the conscious contextualization of lessons. The additional years are further aimed at providing more time for students to prepare for tertiary education, develop mid-level skills for employment, and entrepreneurship (Department of Education, 2016). The K to 12 curriculum also integrates 21 st-century skills in providing a quality 12 -year basic education program for Filipino students ( SEAMEO INNOTECH, 2012; Barrot, 2018). Included in this major reform are the modifications made to the curriculum of the different learning areas across grade levels that affect students' learning experiences, which is a major concern for parents. These changes are also executed at the instruction level, affecting classroom teaching and learning practices.

These private school innovations and government-led changes have a direct impact on children's schooling, thus parents want to be included in the change process -- from planning to implementation, to understand what all these adjustments mean for their children. However, parents were not properly consulted and oriented before the K to 12 implementation. Some parents remained clueless about the changes, even during implementation (Marcelo, 2014). It is upon this scenario of curriculum reforms that this research would like to gain an understanding of educational practices that parents prefer, as well as their underlying beliefs about teaching and learning, particularly in the junior high school subject, English. Together with these curricular reforms is the enhancement of the English curriculum to develop an adequate command of the English language among learners (Barrot, 2018).

This study is based on Dodd's (1998) investigation of parents' beliefs about effective classroom practices for teaching and learning high school English. She determined the explanations parents gave to support their beliefs and examined the assumptions on principles of teaching and learning that appeared to underscore the parents' preferred practices. It further tries to answer the same problems in the implementation of the English curriculum and follows an identical research design and methodology. However, unlike Dodd's study that centered on English 8, this research was expanded to involve English 7 to 9 in Junior High School, as it is one of the central disciplines in the K-12 curriculum. Thus, the objective of this study is to gain an understanding of educational practices that parents prefer particularly in the junior high school subject, English. Specifically, it aims to answer (1) what possible beliefs do parents have about teaching and learning English that leads them to approve or disapprove of certain educational practices, and (2) what problems could be identified within their explanations that could help educators in the improvement of curricular and educational practices. In gaining answers to these questions, the study hopes to be of help to (1) policymakers as they craft baseline competencies; (2) school owners as they implement a nationally prescribed curriculum; and (3) parents themselves as they try to support their children in their goal for scholastic achievement.

\section{Curriculum Implementation}

Curriculum implementation is the process of putting the curriculum document into practice. It also involves executing changes of curricular reforms (Print, 1993) and educational practices. Educational practices are activities and judgments based on theoretical principles and embedded in philosophical traditions (Carr, 1987). At the heart of the educational practice is the curriculum as it guides processes and decisions on program implementation and events inside the classroom.

Successful curriculum implementation is a result of careful planning that considers the interplay of 3 factors: program, people, and processes. Changes are responses to the need for improvement. Thus, the people involved must understand the beliefs and values that lie beneath these changes to grasp how these can better meet program goals. Modifications in curricular processes and educational practices require shifts in perspectives and habits founded on the personal and collective understanding of the implementers and stakeholders about the curriculum (Ornstein and Hunkins, 2009; Fullan, 2007). It is therefore important to make sure that all stakeholders fully understand the changes and the underlying rationale for such reforms to minimize resistance during actual implementation.

The home environment significantly affects how students learn. The parents have a strong influence on their children because from "infancy until the age of 18 , children spend approximately $92 \%$ of their time outside the school under the influence of their parents" (Walberg \& Paik, 2000, p.7). For this reason, cooperation between parents and educators is advantageous to students' 
learning. Dubbed "the curriculum of the home" (Walberg \& Paik, 2000, p.7), the home environment envelopes the interaction between parents and children relating to school matters. These may include the following "conversations about school and everyday events; encouragement and discussion of leisure reading; monitoring and critical review of television viewing and peer activities; deferral of immediate gratification to accomplish long-term goals; expressions of affection and interest in the child's academic and other progress as a person; and perhaps, among such unremitting efforts, laughter and caprice" (Walberg \& Paik, 2000, p.7). These engagements prepare children for school activities and reinforce what they learned in a class inside and outside the school.

\section{The K to 12 English Curriculum}

The K-12 English Curriculum, also known as the K-12 Language Arts and Multiliteracies Curriculum (LAMC), is a response to students' poor performance in national achievement tests across subjects (Department of Education, 2016; Barrot, 2018). It believes that language is the basis of all communication and is the foundation of all human relationships. It is anchored on the following language acquisition, learning, teaching, and assessing principles (Department of Education, 2016):

1. All languages are interrelated and interdependent;

2. Language acquisition and learning is an active process that begins at birth and continues throughout life;

3. Learning requires meaning;

4. Learners learn about language and how to use it effectively through their engagement with and study of texts;

5. Successful language learning involves viewing, listening, speaking, reading, and writing activities; and

6. Language learning involves recognizing, accepting, valuing, and building on students' existing language competence, including the use of nonstandard forms of the language, and extending the range of language available to students.

The LAMC has four (4) components. Component 1 is a language learning process where teachers are guided by the six (6) language teaching principles - spiral progression, interaction, integration, learner-centeredness, contextualization, and construction. These principles explain the natural process of language development. Component 2 is effective language use that highlights understanding cultures, language, process, and strategies as essential knowledge and skill areas. Component 3 is making meaning through language. It shows the interdependence and interrelationships of the macro-skills of language (listening, speaking, and viewing; reading, viewing and responding; and writing and representing) and the development of thinking skills (critical thinking, creative thinking, and metacognition). Component 4 is a holistic assessment. It characterizes proximity to actual language use and performance, holistic view of language, integrative view of learning, developmental appropriateness, and multiple referencing (Department of Education, 2016).

The advancements and new applications of technology, and the importance placed on cultural diversity and globalization have changed the concept of 21 st-century learning. This ability includes using available resources to collect, organize, manage and generate accurate information, evaluating the relevance, quality, and usefulness of information gathered, and generating accurate information using available resources (Educational Testing Service, 2007 in Barrot, 2018). The LAMC was reviewed and enhanced to heed this call to address 21 st-century learning. Some changes that were introduced in the LAMC are the decongestion of the minimum learning competencies and standards, the adoption of the Mother Tongue-Based Multilingual Education (MTBMLE) from grades 1 to 3, the reduction of the time allotment for English subjects in elementary and junior high school levels from five hours to 4 hours per week at the secondary level, the use of an end-of-grade assessment scheme (Barrot, 2018), and the conscious utilization of student-centered approaches to learning (Department of Education, 2016).

\section{Methodology}

The research design is qualitative and descriptive to investigate parents' concerns, beliefs, and ideas regarding the Junior High School (JHS) English Curriculum and its implementation. Key informant interview (KII) was used as the main data-gathering technique. The utterances and information from the KII were subjected to thematic analysis, which provided the major patterns and ideas that are important in answering the research questions. The parameters used were drawn from the research questions, the grounded theory framework, and Dodd's original interview guide. With the latter's consent, the interview guide was prepared and contextualized to the Filipino parents' context. 


\section{Locale and sampling}

The study was conducted in Quezon City, Philippines, about 13 kilometers away from the capital city of Manila. The participants were parents whose children attended a private, non-sectarian school with a Junior High School program — the level needed for the study.

Purposeful sampling was utilized to determine respondents. The seventeen (17) parents of JHS students were the participants of this study. Out of the seventeen, thirteen (13) are females, while four (4) are males. The participants came from diverse backgrounds and their levels of educational attainment range from high school diploma to Master Degree. The nationality of the parents is mostly Filipino, with 1 Indian and 1 Korean.

This study's results apply only to the school involved in the research and may not be readily generalized in other settings. However, the method may be duplicated to gather parents' ideas and feedback about the school's program and practices.

\section{Instrumentation and analysis}

The tool used for data collection was the interview guide used by Dodd (1988) in her original study. Permission from Dodd was obtained for the use of the said interview guide, which was subsequently contextualized to suit the Philippine setting. Since the interview guide was already used in a previous study, it is assumed that the instrument chosen is valid and reliable.

Thematic analysis was used to treat the data gathered from the interviews. The themes were derived using a series of coding processes (Vaismoradi et al., 2016). Parents' utterances were initially transcribed, coded, and grouped according to similar concepts. The concepts were then classified and coded again into larger constructs. Finally, themes were then drawn from categorizing the constructs. (Cresswell, 2003; Vaismoradi et al., 2016).

\section{Emergent Themes}

Below are the themes that were generated from the interviews.

\section{Parents' beliefs on English curriculum implementation}

Parents believe that the approach to the English curriculum is primarily interactive. Students should also be provided with opportunities, to a certain degree, to choose the topics they wish to read or write about.

Generally, the parents see literature, composition, writing, and grammar as necessary learning areas that would help their children attain successful careers. While some parents suggest providing more group work to enable scaffolding and student learning in learning these topics, others see the significance of lectures and individual work, while others recommend a balance between individual and group work. However, the respondents agree the teacher is the leader who takes charge of the classroom while providing the necessary guidance and assistance. The use of computers and visual aids is also encouraged. Respondents agree that zero interaction in the classroom should be avoided.

The primary considerations in lesson planning and choosing teaching strategies are the subject or topic's requirements, the students' interests, needs and personality, and appropriateness to both the subject and students. Relevance to the students is also mentioned as an important factor.

There is no disagreement with the learning areas of the English program. They see literature, grammar, and composition writing as essential knowledge that would maximize the students' potentials and help them attain successful jobs or careers.

Moreover, respondents equate quality experiences with what the school provides. For them, their children's actual experiences in the school are already ideal, even if it is not entirely perfect. They are happy that their children's stories about school experiences are positive.

\section{Parents' beliefs on teacher's duties and responsibilities/ parents expectations of a teacher}

Parents view teachers as leaders, managers, and role models in the classroom. They should also be experts in the subject matter and in knowing each student's capabilities and characteristics. The teacher must guide and discipline the students. 
The teacher should set boundaries and limits to their relationship with students. However, the respondents' answers regarding the relationship with students vary. Some note that it should be formal but not too detached, while others think that an informal relationship where teachers and students have bonding moments is essential in fostering a conducive learning environment. In the end, the parents agree that the relationship characterized by respect should be cultivated to ensure healthy interaction among students and teachers.

\section{Parents' beliefs on parent-teacher relationship}

Parents trust that the teachers know what is best for the implementation of the English program. Some noted that they would only talk to teachers regarding the grades and academic progress of their children. However, parents would like to be more actively involved in partnering with teachers so they could also help their children at home. The home-school link is important for them, as they only have their children's best interests in mind, and they also see themselves as "teachers" at home.

The respondents think that interaction between parents and teachers should be formal, with mutual respect and understanding that they only want what is best for the students. Regarding concerns or issues, both should also try to understand where each side is coming from.

\section{Parents' beliefs on school environment}

Parents deem the school environment as an essential part of their children's learning experiences. They see classroom interactions as the foundation for promoting the school environment. Central to the quality of learning experiences is the teacher's guidance and assistance. They believe that the teacher should set a conducive learning atmosphere during class.

Part of the school environment is the cultivation of the school culture. The parents describe school culture as the values and beliefs espoused by the school. They trust in the school's core values and would like their children to teach these. While some parents are against developing individual culture or subculture among students, all are in agreement that the school culture should be realized.

\section{Discussion}

\section{On parents beliefs about teaching and learning English that leads them to approve or disapprove of educational practices}

Parents' ideas about teaching and learning English are largely based on experiences -- theirs and their children's. While they have experienced the more traditional teacher-centered approach, they also see the school's student-centered approach's benefits and hear positive experiences from their children. This explains why some parents have conflicting ideas about the approaches and strategies used inside the classroom. For example, they suggest teacher-centered approaches such as lectures and provide a standard teacher's interpretation of a text, but at the same time, they advocate for student-centered strategies such as group work, scaffolding, and allowing students their textual interpretations. They further view the quality of student engagement or interaction as a primary factor in maximizing learning. Accordingly, parents are more inclined to accept reforms based on their children's feedback and how these may positively affect student learning. While parents tend to lean on teacher-centered strategies due to their own experiences, they are open to the shift in student-centered methods because they see how this addresses students' interests, and maximizes their children's participation in a class.

Moreover, parents believe that the teacher plays a significant role in the teaching-learning process. The teacher is the primary figure in the classroom, whose decisions affect student learning. The teacher has to cultivate a conducive learning atmosphere by setting limits and standards to the quality of interaction and engagement inside the classroom. Teachers should also plan and implement lessons based on the relevance to the topic, as well as the students' needs, interests, and personalities. The teacher should also be cognizant of the students' characteristics and needs to guide and assist each one appropriately. How the teacher manages the class and the lesson is key to unlocking their children's potential. The parents are appreciative of what the teachers do for their children. Accordingly, the parents do not question the content or strategies used in the delivery of the English Junior High School curriculum because of the trust and respect they place on the teacher's role as the primary facilitator of learning. Rather, they generally support what the school is doing. A few have suggestions regarding specific strategies but these are based on their feelings and experiences. 


\section{On problems, the school and educators could identify and address}

The parents' primary concern is their children's well-being and value education as the key to unlocking their children's potential. They further believe that the school can provide the necessary learning experiences for their children to succeed. Thus, the parents are supportive of the school and have a positive view of what the school espouses. However, a deeper look at the parents' responses reveals that there are concerns that the school and the teachers need to address.

\section{a. English curriculum implementation}

There is no disagreement with the learning areas of the English program. They see that literature knowledge, grammar, and composition writing skills are essential competencies that would maximize the students' potentials and help them attain successful jobs or careers. However, there should be a give and take in the activities and materials to be read in class. While materials on literature classics must be taken up as a baseline standard, additional reading materials must have subject matters that are relevant to the child's interests, needs, and personality.

Parents believe that their children's learning would be enhanced further if they can apply their lessons outside school. Part of this set-up is allowing children to choose their text for reading and develop their writing styles. This way, parents suggest giving children opportunities to choose writing and reading topics based on their interests. While the parents understand the need to follow prescribed readings and standard writing formats, the students do not read and follow these prescribed books and formats in real life.

\section{b. Teacher's role and duties}

Parents view teachers as role models and subject matter experts. They further pointed out that teachers should balance professionalism and a personalized approach in establishing relationships with students and parents. Their responses indicate that schools must look at soft skills apart from subject matter specialization in their hiring process. Soft skills are non-technical skills related to how one accomplishes a task or job. They include ones' interaction with co-workers, problem-solving strategies, and work management (Doyle, 2020). Similarly, existing teaching personnel must constantly be trained on interpersonal skills and must be given sufficient preparation and training before their subject or class assignment.

\section{c. Parent-Teacher Relationship}

A major concern is strengthening the home-school connection, especially in reinforcing lessons at home. Thus, parents also want to better understand the lessons because they want to guide their children at home. Parents seek more involvement because they want to take part in their children's learning process.

Parent involvement is the "dedication of resources by the parent to the child within a given domain" (Grolnick and Slowiaczek in Grolnic, et al, 1997, p. 538). One of six forms of parent involvement is school-home communication (Epstein in Patel \& Stevens, 2010). When parents believe they are efficacious in helping their child with homework, they would continue to be involved in this area (Goodnow in Grolnick, et al, 1997). Given the educational background of most of the respondent parents, the willingness to be involved seems consistent with Grolnick, et al (1997). While schools cannot choose their students based on parents' educational attainment to foster a good school-parent relationship, it would be useful for teachers and school administrators to develop school-home communication and partner strategies based on this.

\section{d. School environment}

Parents who enroll their children in a particular school approve of the school's environment, which they believe to result from the reinforcement of values taught in the classroom. Furthermore, parents believe that being part of the school's culture provides for a better learning experience. However, their concerns are in the unintended culture and subculture from which becomes the source of bullying and school gang violence. In this light, parents call upon the teachers to provide guidance and consciously create an atmosphere conducive to learning.

\section{Conclusions and Recommendations}

Based on the findings, the parents' understanding and appreciation of what is happening in the classroom are based on their own and their children's experiences. Relatedly, their approval of the curriculum and educational practices depends on the impact on 
their children's well-being. Parents are supportive of school reforms especially if the benefits to their children are clearly explained. Furthermore, they believe that the teacher plays a significant role in choosing the learning experiences that would maximize their children's potential, and trusts that teachers will also do what is best for their children. However, the teacher should be guided by the students' interests and needs when planning and implementing lessons. Specifically, the need to consciously incorporate strategies to promote independent learning and mastery of English skills and allow students to explore their own writing style and other text selections based on their own needs and interests.

In terms of the implementation of the English curriculum, parents view the content, namely, composition, writing, literature, and grammar, as essential topics that can help propel the students' success. They also view the level of student engagement as a primary factor in their children's academic success. Adequate quality student interaction is equated with more opportunities to practice and hone their English skills.

Parents can provide information regarding problems and concerns in the areas of curriculum implementation, teachers' roles and duties, relationships with parents and students, and the school environment. They see improvement of policies and practices from the perspective of how these would benefit their children and focus their attention on how these reforms and current systems affect students' well-being. Their relationship with their children also affords them a deeper appreciation and insight into how lessons are applied at home and the influences of the students' school culture as expressed through their behavior and stories. In this light, we need to view parents as partners in managing students' learning, not as obstacles to reforms or innovations.

Schools and their teachers can further address challenges and gain the parents' support by strengthening home-school partnerships. The school engages parents as partners in the students' educational journey and allows the reinforcement of learning at home. This partnership also addresses the parents' need to be more involved in their children's learning process by guiding them at home, especially when students are afforded the freedom to read texts based on their interests.

Therefore, engaging parents provides rich insights regarding problems that need to be addressed about the curriculum and its implementation. After all, the parents are one of the major stakeholders and know their children best. Thus, it would be beneficial for schools to get their perspective and active involvement in curriculum practices and processes. School policies on home-school partnership should be reviewed to provide opportunities for parents and teachers to collaborate. This would provide a more intimate venue outside the school, the home, where students can apply and enhance their English skills. Furthermore, teachers should also provide constant feedback to parents on their child's progress, as well as explore using homework that would entail parent involvement.

The significance of parent engagement lies in knowing that their views and feedback are significant information that may potentially guide or add to the school's educational policies and practices for curriculum implementation, especially about what else may be done to assist students, and how the curriculum may be expanded to include application and alignment with the students' home environment. Thus, we also recommend that parents of children attending public schools should also be included in a similar study because they come from a different context. Likewise, their input on curriculum practices and policies would provide another dimension to the study.

\section{References}

Abelson, R. B. (1979) Differences between belief and knowledge systems. Cognitive Science 3, $355-366$

Barrot, J. (2018). English curriculum reform in the Philippines: Issues and challenges from a 21 st-century learning perspective. Journal of Language, Identity \& Education, 18, 1-16. https://doi.org/10.1080/15348458.2018.1528547.

Bartolome, M. T., Mamat, N., \& Masnan, A. H. (2017). Parental Involvement in the Philippines: A Review of Literatures. International Journal of Early Childhood Education Care, 6, 41-50.

Carr, W. (1987), What is an Educational practice?. Journal of Philosophy of Education, 21, 163-175. https://doi.org/10.1111/j.1467-9752.1987.tb00155.x

Creswell, J. W. (2003). Research design: Qualitative, quantitative, and mixed methods approaches (2nd ed.). Thousand Oaks, CA: Sage.

Creswell, J. W. (2008). Educational Research. New Jersey: Pearson Education, Inc. 
de Guzman, A. B., de Castro, B. V., Aquino, K. B., Buenaventura, M. R., Duque, A. C., \& Enriquez, M. D. (2008). Filipino parents' school choice and loyalty: a factor analysis. Educational Research for Policy and Practice, 7(2). https://doi.org/10.1007/s10671-007-9037-7

Department of Education. (2016). K-12 English Curriculum Guide. Retrieved from http://www.deped.gov.ph/sites/default/files/page/2017/English\%20CG!.pdf

Dodd, A. W. (1998). What educators learn from parents who oppose curricular and classroom practices. Journal of Curriculum Studies, 30(4), 461-477.

Doyle, A. (2020). What are Soft Skills? Retrieved January 2020, from https://www.thebalancecareers.com/what-are-softskills-2060852

Greene, J. C. (1987). Stakeholder participation in evaluation design: Is it worth the effort? Evaluation and Program Planning, 10(4), 379-394. https://doi.org/10.1016/0149-7189(87)90010-3

Fetalvero, A. F. (2010). How parents' beliefs and expectations influence their investments in children's early learning environment: a social exchange perspective (Thesis). University of North Carolina

Grolnick, W. S., Benjet, C., Kurowski, C. O., \& Apostoleris, N. H. (1997). Predictors of Parent Involvement in Children's Schooling. Journal of Education Psychology, 89(3), 538-548.

Johnson, J., and Immerwahr, J. (1994). First things first: What Americans expect from the public schools. New York: Public Agenda Foundation.

Lynch, J., Anderson, J., Anderson, A., \& Shapiro, J. (2006). Parents' Beliefs About Young Children's Literacy Development and Parents' Literacy Behaviors. Reading Psychology, 27, 1--20.

Marcelo, E. (2014, October). Parents' group calls for review of K-12 Program. GMA News Online. Retrieved December 2017, from http://www.gmanetwork.com/news/news/nation/382582/parents-group-calls-for-review-of-k-to-12program/story/

Ornstein, A. C., \& Hunkins, F. P. (2009). Curriculum: Foundations, Principles, and Issues (5th Edition ed.). (S. D. Dragin, Ed.) Boston, MA: Pearson Education, Inc.

Patel, N., \& Stevens, S. (2010). Parent-Teacher-Student Discrepancies in Academic Ability Beliefs: Influences on Parent Involvement. The School Community Journal, 20(2), 115-1356.

Philippine Senate and House of Representatives (2013, May). R.A. 10533: Enhanced Basic Education Act of 2013. Retrieved in 2017 from https://www.officialgazette.gov.ph/2013/05/15/republic-act-no-10533/

Rokeack, M. (1960) The Open and Closed Mind. New York: Basic Books.

SEAMEO INNOTECH (2012). K to 12 toolkit: Resource guide for teacher educators, school administrators, and teachers. Quezon City, Philippines: Author.

Stipek, D., Milburn, S., Clements, D., \& Daniels, D. H. (1992). Parents' beliefs about appropriate education for young children. Journal of Applied Developmental Psychology, 13(3), 293-310. https://doi.org/10.1016/01933973(92)90034-F

Vaismoradi, M., Jones, J., Turunen, H., \& Snelgrove, S. (2016). Theme development in qualitative content analysis and thematic analysis. Journal of Nursing Education and Practice, 6, 100.

Walberg, H.J. and Paik, S.J. (2000). Effective educational practices. Retrieved from http://www.ibe.unesco.org/sites/default/files/resources/edu-practices_03_eng.pdf 
Wilhite, J. E. (1973) The response of a small rural community in the Midwest to the recommendations of the AngloAmerican conference on the teaching of English, Unpublished Dissertation, University of Illinois at Urbana Champaign Retrieved: Dodd, Ann (1998) What can educators learn from parents who oppose curricular and classroom practices? Curriculum Studies Journal, 30(4), 461-477

Yee, J. (2015, May). Parents to DepEd: Don't experiment with our kids. Inquirer.net. Retrieved December 2017, from http://newsinfo.inquirer.net/690478/parents-to-deped-dont-experiment-with-our-kids 